girls is because ovarian follicular development depends upon stimulation by both follicle stimulating hormone and luteinising hormone.

By the end of radiotherapy there was clinical, biochemical, and radiological evidence of tumour regression. The $\beta \mathrm{HCG}$ concentration became undetectable and consequently the serum testosterone concentration fell from 28.4 to $1.7 \mathrm{nmol} / 1$ $(98.46 \mathrm{ng} / \mathrm{ml}$ to $5.89 \mathrm{ng} / \mathrm{ml})$. Within $2-3$ months the testosterone concentration rose to $10 \mathrm{nmol} / \mathrm{l}$ $(34.67 \mathrm{ng} / \mathrm{ml})$ and there was an increase in the size of the testes. Gradually over the 2 year follow up period the serum follicle stimulating hormone value rose, associated with an increase in the size of the testes from 3 to $8 \mathrm{ml}$ reflecting normal activity of the hypothalamic pituitary gonadotrophin axis.

Operative intervention in patients with pineal tumours has a high morbidity and mortality. ${ }^{\text {? }}$ Furthermore, as illustrated by our patient, the pineal germinoma is highly radiosensitive and may be cured by radiotherapy alone. ${ }^{8}$ Providing the diagnosis can be made early, and unless a shunt is required, surgery may be avoided. The $\beta$ HCG assay allows such a diagnosis to be made biochemically and we believe that this should be measured in all boys with precocious puberty.

\section{References}

1 Wass JAH, Jones AE, Rees LH, Besser GM. hCG $\beta$ producing pineal choriocarcinoma. Clin Endocrinol $(O x f) 1982 ; 17: 423-31$.

2 Romshe CA, Sotos JF. Intracranial human chorionic gonadotrophin secreting tumor with precocious puberty. J Pediatr 1975; 86: 250-2.

3 Pomarede R, Czernichow P, Finidori J, et al. Endocrine aspects and tumoral markers in intracranial germinoma: an attempt to delineate the diagnostic procedure in 14 patients. J Pediatr 1982; 101 : 374-78.

4 Sklar CA, Conte FA, Kaplan SL, Grumbach MM. Human chorionic gonadotropin-secreting pineal tumor: relation to pathogenesis and sex limitation of sexual precocity. J Clin Endocrinol Metab 1981 ; 53: 656-9.

5 Tanner JM. Growth at adolescence. 2nd edition. Oxford: Blackwell, 1962.

6 Tanner JM, Whitehouse RH, Marshall WA, Healy MJ, Goldstein H. Assessment of skeletal maturity and prediction of adult height (TW2 method). London: Academic Press, 1975.

7 Brady LW. The role of radiation therapy. In :Schmidek HH, ed. Pineal tumours. New York: Masson Publishing, 1977: 127-32.

8 Sung DII, Harisiadis L, Chang CH. Midline pineal tumors and suprasellar germinomas: highly curable by irradiation. Radiology 1978; 128: 745-51.

Correspondence to Dr S R Ahmed, Department of Endocrinology, Christie Hospital and Holt Radium Institute, Manchester M20 9BX.

Received 15 March 1983

\title{
Psychogenic cough
}

\section{A SHUPER, M MUKAMEL, M MIMOUNI, M LERMAN, AND I VARSANO}

Department of Pediatrics B, Beilinson Medical Center, Tel Aviv University Medical School, Petah Tiqva, Israel

SUMMARY Psychogenic cough is croupy and explosive, never occurs during sleep, and is not affected by antitussive drugs. Physical and radiographic examinations of the respiratory tract and microbiological investigations are normal. Bronchial asthma manifested as chronic cough should be excluded in each patient by lung function testing.

Psychogenic factors are known to be a possible cause of persistent cough in children. ${ }^{1}$ In these cases the cough is very disturbing but its aetiology is generally recognised only after a long period of troublesome and expensive diagnostic procedures. The diagnostic delay is in part due to difficulties in differentiating the cough from other chronic respiratory diseases and unfamiliarity with this condition. Although 'psychogenic cough' is not rare, very few detailed descriptions are available in the published reports. ${ }^{2-5}$ We report 6 patients with psychogenic cough and review previously reported cases to alert physicians to this aetiology of cough in children.

\section{Case reports}

Case 1. An 11 year old girl was referred to our out-patient clinic because of persistent cough which had begun 6 months before. The cough was paroxysmal, harsh, barky, and non-productive. It recurred frequently during waking hours but never during sleep and distracted her from school, friends, and social activities. Her past medical history gave no clues and trials with different antibiotics, antihistamines, and antitussives were unsuccessful.

Physical examination, including direct laryngoscopy, revealed no abnormality. Repeated complete blood counts, sputum cultures, and serologic 
studies for viral and mycoplasma infections were negative. Radiographs of chest, paranasal sinuses, larynx, and upper gastrointestinal tract were normal. Pulmonary function tests including lung volumes, forced expiratory volume in 1 second, peak expiratory flow rate, and flow volume curve were normal.

The girl was admitted to hospital for close observation. It was noted that when a member of the medical staff approached her room, she started to cough noisily. A psychological interview revealed that she had an uncontrollable hyperkinetic brother who generated anxiety and tension within the family. Furthermore, the patient had learning difficulties and problems in forming relationships with friends. She did not live up to the expectations of the family with regard to school and social achievements and had become frustrated, tense, and aggressive. The cough was the manner in which she expressed these feelings and gained attention. The whole family was referred to a psychiatric clinic for psychotherapy. During this period they were encouraged to discuss freely the family interrelationships and tensions. When the girl could talk about her problems and frustrations the cough was no more 'needed' and gradually disappeared. In a follow up examination after 6 months she was free of symptoms.

Cases 2-6. A psychogenic aetiology for persistent cough was also shown in 5 other children- 4 boys and 1 girl aged 6 to 11 years (mean 9.0 years). All had a croupy barking bizarre cough that disappeared during sleep. Three patients had a peculiar 'chin on chest' posture while coughing. ${ }^{2}$ The cough was severe and disturbing and all children had lost many school days. Routine diagnostic procedures did not show any abnormality. Bronchoscopy performed in 1 patient and lung function tests in 4, proved to be normal. Our youngest patient, a 6 year old boy did not cooperate in lung function tests. However, a long term follow up after the disappearance of the cough did not reveal any evidence of asthma.

Psychological evaluation revealed school phobia in 2 patients, a reaction to parental divorce in 1 , and a secondary gain from coughing in the remaining 2 , as a possible cause for the persistent cough. The patients and their families were referred to the hospital's psychology counselling service where family problems and their influence on the patients' behaviour were discussed during weekly meetings. Possible solutions to practical problems such as school phobia were offered. In all patients the symptoms disappeared after a few weeks of treatment. In 1 child marked symptomatic relief was obtained after a 1 month course of haloperidol.
Table Clinical data in 22 children* with psychogenic cough, aged 6-15 years (mean 11 years)

\begin{tabular}{lcr}
\hline & $N o$ & $\%$ \\
\hline Girls : boys & $9: 13$ & 100 \\
Barky cough & 22 & 100 \\
Coughing during sleep & 0 & 0 \\
Response to antitussive medications & 0 & 0 \\
History of preceding upper respiratory infections & 6 & 27 \\
'Chin on chest' posture & 6 & 27 \\
Exaggeration of cough in presence of medical staff & 8 & 36 \\
Appreciable school absenteeism & 13 & 59 \\
Bronchoscopies performed (no abnormalities found) & 7 & 32 \\
Pulmonary function tests performed (normal & 6 & 27 \\
results in all) & 12 & 55 \\
School phobia & 7 & 32 \\
Successful response to tranquilisers & 20 & 91 \\
Successful response to psychotherapy & &
\end{tabular}

\section{Discussion}

Psychogenic cough is usually regarded as a respiratory tic and can be precipitated by various emotional stimuli. ${ }^{2} 3$ It may represent a somatic manifestation of a wide range of psychological problems. School phobia, attention seeking, or anxiety were found in children with this disorder. ${ }^{24}$ Berman, however, describing several patients in whom no obvious psychological abnormality was found considered the cough in these cases to be a habit formed after previous respiratory diseases, ${ }^{5}$ and it should be noted that in $27 \%$ of the patients there was a history of upper respiratory infection preceding the cough (Table).

A cough of psychogenic origin has well defined clinical characteristics (Table). It is usually croupy, barky, and explosive and disappears during sleep. It is resistant to antitussive medications. A typical "chin on chest' posture with the hand held to the neck while coughing may be noticed in some of the patients. ${ }^{2}$ The physical examination of respiratory systems as well as routine laboratory studies, extensive microbiologic and radiographic investigations, and lung function tests do not reveal any relevant abnormality.

Since asthma may manifest as a chronic cough without obvious wheezing, baseline and sometimes provocative lung function testing should be performed ${ }^{6}$ even in patients with an evident psychogenic background for the cough. Unfortunately these tests were not performed in previously published cases. More compound and invasive diagnostic procedures such as bronchoscopy are rarely indicated.

In mild and uncomplicated cases the treatment is usually simple. Explanation, suggestion, and discussion of the problems that appear to be associated with the psychogenic origin of the cough may be satisfactory treatment for many of the patients. In severe and problematic cases referral for psychiatric 
consultation should be considered. Treatment with tranquilisers brought about an improvement in some patients, including 1 in our study (Table). The use of tranquilisers should, however, be temporary only and these should not be used as a substitute for psychotherapy.

The physician's awareness of the possibility of psychogenic factors in the aetiology of persistent cough may help in early diagnosis and thus repeated troublesome, unnecessary, and expensive investigations may be avoided and the proper treatment be undertaken sooner.

We thank Dr T Scheinfeld for reading the manuscript and for his valuable suggestions.

\footnotetext{
References

1 Mellis CM. Evaluation and treatment of chronic cough
} in children. Pediatr Clin North Am 1979; 26: 553-64.
2 Weinberg EG. 'Honking'; psychogenic cough tic in children. S Afr Med J 1980; 57: 198-200.

3 Berstein L. A respiratory tic: 'the barking cough of puberty'; report of a case treated successfully. Laryngoscope $1963 ; 73$ : 315-9.

4 Kravitz H, Gomberg RM, Burnstine RC, Hagler S, Korach A. Psychogenic cough tic in children and adolescents: nine case histories illustrate the need for reevaluation of this common but frequently unrecognized problem. Clin Pediatr (Phila) 1969; 8: 580-3.

5 Berman BA. Habit cough in adolescent children. Ann Allergy 1966; 24: 43-6.

6 Corrao WM, Braman SS, Irwin RS. Chronic cough as the sole presenting manifestation of bronchial asthma. N Engl J Med 1979; 300: 633-7.

Correspondence to A Shuper, Department of Paediatrics B, Beilinson Medical Center, Petah Tiqva 49100, Israel.

Received 18 May 1983

\section{Cardiovascular anomalies with imperforate anus}

\section{O H P TEIXEIRA, K MALHOTRA, J SELLERS, AND S MERCER}

\section{The Departments of Pediatrics and Surgery, Children's Hospital of Eastern Ontario and the} University of Ottawa, Ottawa, Canada

SUMMARY In 68 patients with anorectal malformations cardiovascular anomalies (CVA) were seen in 15 and genitourinary (GU) anomalies in 30. CVA were more frequent $(33 \%)$ whenever there was a GU anomaly. Ventricular septal defect was the most frequent lesion. All but 1 CVA occurred with type III anorectal malformation. The complexity of the cardiac lesion did not parallel that of the GU anomaly.

The incidence of imperforate anus (IA) has ranged from 1 in 1500 to 1 in 5000 births $^{1}$ and cardiovascular anomalies (CVA) may be present in $8-17 \%$ of these. ${ }^{2} 3$ In 1 report only, however, were the cardiac lesions outlined. ${ }^{3}$ Our study was undertaken to determine the type of CVA associated with IA and to establish any correlation between CVA and (i) the anatomic type of anorectal anomaly, (ii) the presence of additional anomalies, especially of the genitourinary (GU) system, and (iii) the degree of complexity of the GU anomaly.

\section{Patients and methods}

The records of all 68 patients with anorectal anomalies seen at our hospital from 1974 to 1982 were reviewed. Forty nine infants were referred because of anal anomaly and the remainder because of multiple abnormalities. Twenty three had been seen previously elsewhere. The diagnosis was made in the newborn period in 66 patients. The initial assessment consisted of physical examination, radiographs, and other tests as required. All patients but 2 with any possibly abnormal cardiovascular findings were seen by a paediatric cardiologist. The anorectal anomalies were classified according to Ladd and Gross-type I, anal stenosis and partial obstruction; type II, imperforate anal membrane; type III, imperforate anus and rectum ending as a blind pouch at variable distance from the skin; type IV, normal anal canal, sphincter, and lower rectum, but upper rectum ending blindly some distance above. ${ }^{1}$

\section{Results}

Twelve patients had type I anorectal anomaly, 1 had type II, and the remainder had type III. There were 43 boys and 25 girls. The associated anomalies are presented in the Table. There were 15 (12 boys, 3 girls) with CVA. GU anomalies were present in 30 infants, and 10 of them also had a CVA. Of the remaining 38 patients, only 5 had a CVA $(P<0.05$, $\left.\chi^{2}\right)$.

Ventricular septal defect, seen in 6 patients, was the most common cardiac lesion. Two premature 